\title{
Evaluation of Subsurface Fatigue Damage in Strip Mill Rolls by an X-ray Diffraction Method*
}

\author{
By Hiroshi TAKECHI, ${ }^{* *}$ Kazuo NAMBA,** Keizo FUJIWARA** \\ and Kouichi KAWASAKI**
}

\begin{abstract}
Synopsis
The X-ray diffraction line profile analysis technique has been applied to the study of fatigue damage below the surface of the work and the backup rolls of a cold strip mill, and the backup rolls of a hot strip mill. Half value breadth has been taken as a measure of fatiguing.

The fatigued zone below the surface of the rolls correlated well with the half contact length, L, being $0.03 \mathrm{~L}$ in the work roll of cold strip mill and $0.1 \mathrm{~L}$ in the other rolls. Changes in the half value breadth with an increase in the number of cycles of roll contact differ according to the surface hardness of the roll: continued cycling results in a decrease in the half value breadth at the surface in hard rolls $(H s \geqq 60)$, and an increase in soft rolls $(H s \leqq 50)$. This technique, the $X$-ray study of fatigue, can be extended to the prediction and prevention of accidental failure of rolls due to fatigue fracture such as spalling. Furthermore, the amount of surface dressing at regular maintenance of rolls can be saved significantly on the basis of an accurate evaluation of the depth of the fatigue damaged zone.
\end{abstract}

\section{Introduction}

An important subject in equipment maintenance is the non-destructive detection of fatigue damage, to prevent fracture accidents. The steel industry requires the development of non-destructive detection methods for fatigue damage in order to secure stable operation, effective utilization and reduction in maintenance cost. Especially, if the initiation of visible cracks can be predicted, the advantages will be very great.

Concerning the fatigue of metallic materials, a large number of studies ${ }^{1,2}$ have so far been made on the fatigue limit from the standpoint of mechanical engineering, and on the structural changes during fatigue from the standpoint of physical metallurgy. However, there are only a few studies available on the quantitative evaluation of fatigue damage.

For example, Miner's law ${ }^{3)}$ uses the ratio of the number of stress cycles to the number of cycles to fracture as a criterion for evaluating fatigue damage, and does not allow fatigue damage to be directly evaluated quantitatively.

The X-ray diffraction method had been used to clarify the phenomenon of fatigue in metallic materials. Studies have also recently started on the nondestructive and quantitative detection of fatigue damage, using measurements of the half value breadth of an X-ray diffraction line. Fundamental studies ${ }^{4-6)}$ in connection with this have already been made by S. Taira et al., and later by the Committee for X-ray Study on Deformation and Fracture of Solid Ma- terials, of The Society of Materials Science, Japan. It is likely that this method will be put to practical use, since a counter system has been developed. The $\mathrm{X}$-ray diffraction method is characterized in that it is very effective in detecting fatigue damage before the initiation of visible cracks, compared with other flaw detection methods such as ultrasonic flaw detection. However it has one disadvantage, that the measuring depth is limited to 20 to $50 \mu$ below the surface.

Among the various steelmaking facilities that suffer from the problem of fatigue, strip mills rolls were chosen by the authors as the subject of this study. The cost of these rolls constitutes a large proportion of the total rolling costs. To achieve a cost reduction, there is a demand for: ( 1 ) the minimizing of the amount of regular dressing and (2) the prevention of roll fracture accidents such as spalling (called also case crashing). It is desirable to reduce the amount of regular dressing to as small a quantity as possible. However, if the amount were to be reduced without a quantitative knowledge of the roll fatigue damage, the number of roll fracture accidents would increase and this would result in an increased total roll cost. Therefore, it is exceedingly difficult to decide on an optimum regular dressing, and it has become the practice to do so empirically. Only two or three previous attempts ${ }^{7,8)}$ have been made to quantitatively measure roll fatigue damage depth so as to decide the minimum necessary dressing.

This report presents measurements of the fatigue damage occurring in strip mill rolls, conducted using the counter type X-ray diffraction method, and an examination of the optimum regular dressing. Rolls for both hot and cold steel strip mills were selected for study. Backup rolls (HBR's) were selected for the measurements on hot rolling rolls, and both work rolls (GWR's) and backup rolls (GBR's) were selected for the measurements on cold rolling rolls. Since HBR's are always kept below $200^{\circ} \mathrm{C}$ during rolling, this report was limited to rolls used in the cold rolling temperature range (in which recrystallization does not occur, nor any notable recovery). The fatigue damage near the surfaces was measured using the change in the half value breadth of the diffraction lines of characteristic X-rays (For the definition of the half value breadth see Ref. 9)). A model experiment on rolling contact fatigue using small test specimens was also conducted.

\footnotetext{
* Originally published in Tetsu-to-Hagané, 65 (1979), 2067, in Japanese. English version received December 10, 1979.

** Technical Research and Development Bureau, Kimitsu Works, Nippon Steel Corporation, Kimitsu, Kimitsu 299-11.
} 


\section{Detection of Fatigue Damage in Strip Mill Rolls}

\section{Experiment}

The rolls selected for measurement are those used in the strip rolling process at the Cold and Hot Strip Mills of Kimitsu Works, Nippon Steel Corp. Table 1 shows the chemical compositions, hardness, structures, etc. of the surface layers of some rolls. The rolling results of the rolls tested are shown in Table 2 . In tables or figures the symbol $\phi$ indicates diameter. The maximum pressure, $P_{\max }$, which represents the Hertzian stress ${ }^{1)}$ generated between the work roll and the backup roll, is a value calculated on the assumption that the rolling force is uniform in the axial direction. The number of rolling contacts, $\mathcal{N}$, represents the number of contacts for each use of a roll (between on dressing and the next). The half contact length, $L$, was determined in the same manner as $P_{\max }$. The wear depth is the value for each use of a roll.

Measurements were conducted on the following three items:

1) Distribution of the half value breadth in the depth direction before use.

2) Distribution of the half value breadth in the depth direction after use.

3) Changes in the half value breadth on the surface, caused by an increase in the number of rolling contacts.

An X-ray diffraction stress-analyzer made by Shimazu Seisakusho, Ltd., was used for the measurements. Table 3 shows the measurement conditions. Although the counter scanning speed and time constant for the work rolls were different from those for the backup rolls, this difference has only a small effect on the half value breadth since the product of both parameters was kept constant. The counted rates for the diffraction lines obtained by continuous scanning were recorded using a rate-meter, on a chart. The diffraction lines showed broad patterns with no saddle points.

The half value breadth was obtained as the difference between the diffraction angles at the two intersecting points of a straight line, parallel to the background and halfway between the background the peak point without separation of the $K \alpha_{1}$ and $K \alpha_{2}$ lines, and a diffraction line. The measured points on each roll were at the middle and end portions of the barrel (about 100 to $200 \mathrm{~mm}$ away from the ends). Gradual removal of the roll surface layer, for the measurement

Table 3. X-ray diffraction line half value breadth measurement conditions.

\begin{tabular}{r|l|l}
\hline 1 & X-ray & Cr K $\alpha$ \\
2 & Filter & $V$, at the receiving slit \\
3 & Diffraction plane & $\alpha \mathrm{Fe}\{211\}$ \\
4 & Slits & Parallel beam, 0.4 \\
5 & Irradiation mask & $8 \mathrm{~mm} \times 4 \mathrm{~mm}$ \\
6 & Irradition area & $12 \mathrm{~mm} \times 2 \mathrm{~mm}$ \\
7 & Tube voltage & $30 \mathrm{kV}$ \\
8 & Tube current & $10 \mathrm{~mA}$ \\
9 & Counter & Scintillation counter \\
10 & Counter scan speed & $1^{\circ} / \mathrm{min}\left(2^{\circ} / \mathrm{min}\right)$ \\
11 & Time constant & $16 \mathrm{sec}(8 \mathrm{sec})$ \\
12 & Range of $2 \theta$ & $145^{\circ} \rightarrow 169^{\circ}\left(148^{\circ} \rightarrow 164^{\circ}\right)$ \\
\hline
\end{tabular}

( ) : for backup rolls

Table 1. Specification of mill rolls tested and experiment specimen.

\begin{tabular}{|c|c|c|c|c|c|c|c|c|c|c|c|}
\hline \multirow{2}{*}{ Shop } & \multirow{2}{*}{ Roll } & \multirow{2}{*}{ Symbol } & \multirow{2}{*}{$\begin{array}{l}\text { Size of } \\
\text { barrel } \\
(\mathrm{mm})\end{array}$} & \multicolumn{5}{|c|}{ Chemical composition (wt \%) } & \multirow{2}{*}{$\begin{array}{l}\text { Manu- } \\
\text { facturing } \\
\text { process }\end{array}$} & \multirow{2}{*}{$\begin{array}{l}\text { Hardness } \\
\qquad(\mathrm{Hs})\end{array}$} & \multirow{2}{*}{$\begin{array}{l}\text { Surface } \\
\text { structure }\end{array}$} \\
\hline & & & & G & $\mathrm{Si}$ & $\mathrm{Mn}$ & $\mathrm{Cr}$ & Mo & & & \\
\hline Cold rolling & Work roll & GWR & $\begin{array}{l}500 \sim 600 \phi \\
\times 2100\end{array}$ & 1.0 & 0.3 & 0.3 & 2.0 & 0.3 & Forge & $80 \sim 97$ & Martensite \\
\hline Cold rolling & $\begin{array}{l}\text { Backup } \\
\text { roll }\end{array}$ & $\mathrm{CBR}$ & $\begin{array}{l}1400 \sim 1600 \phi \\
\times 2100\end{array}$ & 0.5 & 0.3 & 0.3 & 2.0 & 0.3 & ” & $55 \sim 72$ & Bainite \\
\hline $\begin{array}{l}\text { Hot rolling } \\
\text { (Rough) }\end{array}$ & " & HBR & $"$ & 0.7 & 0.4 & 1.0 & 1.0 & 0.4 & Cast & $43 \sim 50$ & $"$ \\
\hline $\begin{array}{l}\text { Hot rolling } \\
\text { (Finish) }\end{array}$ & ” & HBR & " & 0.7 & 0.4 & 0.7 & 3.0 & 0.4 & Forge & $50 \sim 68$ & ” \\
\hline \multicolumn{3}{|c|}{ Experiment specimen } & $100^{\phi} \times 10$ & 0.4 & 0.3 & 0.3 & 0.7 & 0.2 & Rolled & 75 & , \\
\hline
\end{tabular}

Table 2. Rolling results of the rolls tested.

\begin{tabular}{|c|c|c|c|c|c|c|c|c|c|}
\hline Shop & Roll & Symbol & Number & Mill & $\begin{array}{c}\text { Stand } \\
\text { No. }\end{array}$ & $\begin{array}{c}\text { Maximum } \\
\text { pressure } \\
P_{\max } \\
\left(\mathrm{kg} / \mathrm{mm}^{2}\right)\end{array}$ & $\begin{array}{l}\text { Number of } \\
\text { rolling contacts } \\
\mathcal{N} \text { (cycle) }\end{array}$ & $\begin{array}{l}\text { Half } \\
\text { contact } \\
\text { length } \\
L(\mathrm{~mm})\end{array}$ & $\begin{array}{l}\text { Wear } \\
\text { depth } \\
\left(\mathrm{mm}^{\phi}\right)\end{array}$ \\
\hline Cold rolling & Work roll & GWR & 8 & $\begin{array}{l}5 \text { stand } \\
\text { tandem } 4 \mathrm{Hi}\end{array}$ & $1 \sim 3$ & 105 & $4 \sim 24 \times 10^{4}$ & 3.7 & $<0.05$ \\
\hline Cold rolling & $\begin{array}{l}\text { Backup } \\
\text { roll }\end{array}$ & GBR & 6 & ” & 4,5 & 106 & $0 \sim 1.4 \times 10^{6}$ & 3.6 & $<0.1$ \\
\hline $\begin{array}{l}\text { Hot rolling } \\
\text { (Rough) }\end{array}$ & $"$ & HBR & 2 & $\begin{array}{l}\text { Single stand } \\
4 \mathrm{Hi}\end{array}$ & 4 & 130 & $1 \times 10^{5}$ & 7.0 & 1.2 \\
\hline $\begin{array}{l}\text { Hot rolling } \\
\text { (Finish) }\end{array}$ & $"$ & HBR & 5 & $\begin{array}{l}7 \text { stand } \\
\text { tandem } 4 \mathrm{Hi}\end{array}$ & $2 \sim 6$ & 120 & $2 \sim 4 \times 10^{5}$ & 5.5 & 0.4 \\
\hline
\end{tabular}


of the distribution of the half value breadth in the depth direction, was carried out by electrolytic polishing.

For the CWR's, small pieces were cut from the surfaces after rolling and observed in a transmission electron microscope.

\section{Experiment Results}

1. Distribution of the Half Value Breadth before Use Results are shown in Fig. 1. The half value breadth of the CWR's before use is essentially constant up to $0.25 \mathrm{~mm}$ in depth. For the HBR's, the half value breadth is constant, except for an increase at the surface. There is no possibility that a fatigue damage layer might have remained on the HBR surface when the dressing amount (ordinary $2 \mathrm{~mm}$ or more decrease in diameter) and the wear depth are taken into consideration. Consequently, it can be said that a dressing-affected layer of an HBR is present only very close to the surface, i.e., within $0.05 \mathrm{~mm}$ of the surface. In the case of the CWR's, dressing caused no change in the half value breadth, and the dressing-affected layer is considered to be of a negligible depth.

\section{Distribution of the Half Value Breadth after Use}

Figure 1 shows results for the distribution of the half value breadth in the depth direction after use. The distribution of the half value breadth of the GWR shows a decrease toward the surface within $0.1 \mathrm{~mm}$ from the surface. For depths greater than $0.1 \mathrm{~mm}$,

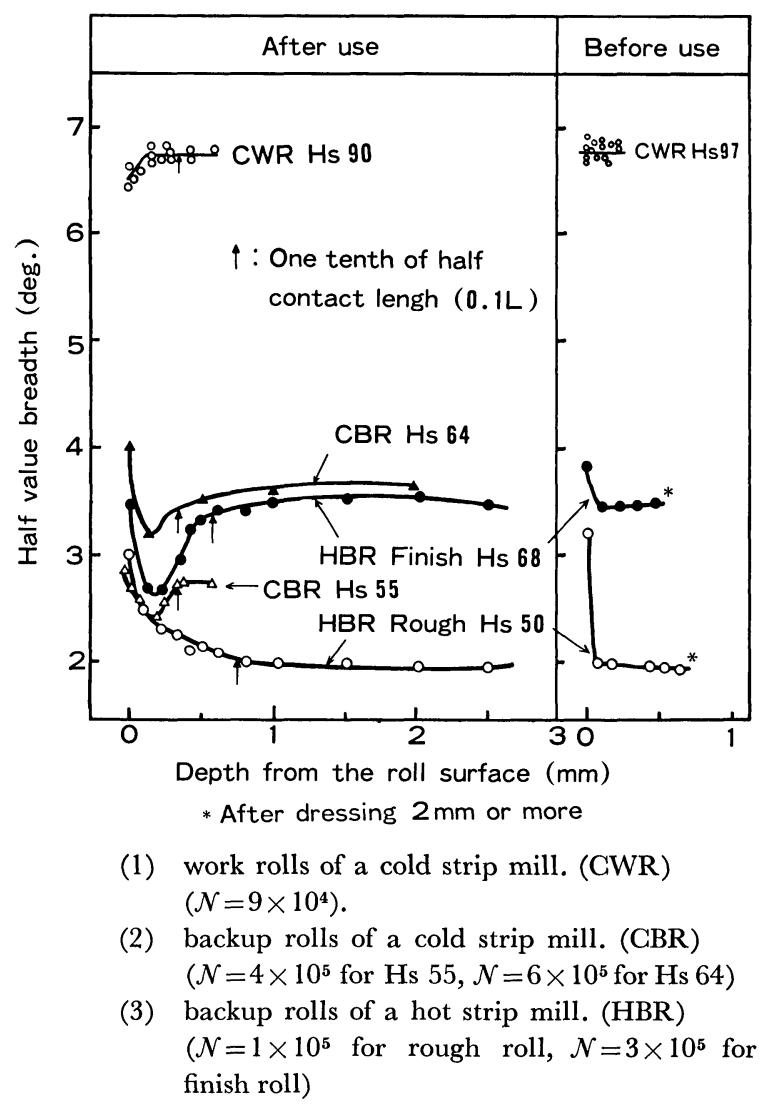

Fig. 1. Distribution of the half value breadth below the surface before and after use. $\mathcal{N}$ is the number of rolling contacts of the roll per period of use. the half value breadth is almost constant, and is identical to the initial value of the material. The arrows in Fig. 1 indicate $0.1 \mathrm{~L}$, one tenth of the half contact length, $L$. For the CWR, the changes in the half value breadth are limited to within $0.03 \mathrm{~L}$ below the surface.

Photograph 1 shows transmission electron microphotographs of the CWR after use. The boundaries of the martensite laths are in general clearly visible $1 \mathrm{~mm}$ below the roll surface (considered not to have suffered from fatigue). However $10 \mu$ below the surface (considered suffering from fatigue), these boundaries are not clear, and the structure itself looks like subgrains.

For the CBR, the half value breadth changes occur within $0.3 \mathrm{~mm}$ of the surface. In this region, the half value breadth is at a maximum at the surface, and has a minimum $0.15 \mathrm{~mm}$ below the surface. At depths greater than $0.3 \mathrm{~mm}$, the half value breadth becomes constant, and is considered to be identical to the initial value of the material. The region in which a change in the half value breadth was observed corresponded to $0.1 \mathrm{~L}$.

In the case of the HBR, a change in the half value breadth occurred within about $0.6 \mathrm{~mm}$ of the surface, and can be said to have occurred within $0.1 \mathrm{~L}$. The pattern of change for an $\mathrm{HBR}$ for rough rolling is different from that for an HBR for finish rolling. An HBR for finish rolling (high-hardness) shows a similar distribution to a GBR. In contrast to this, an HBR for rough rolling (low-hardness) shows a distribution that the half value breadth increases monotonically

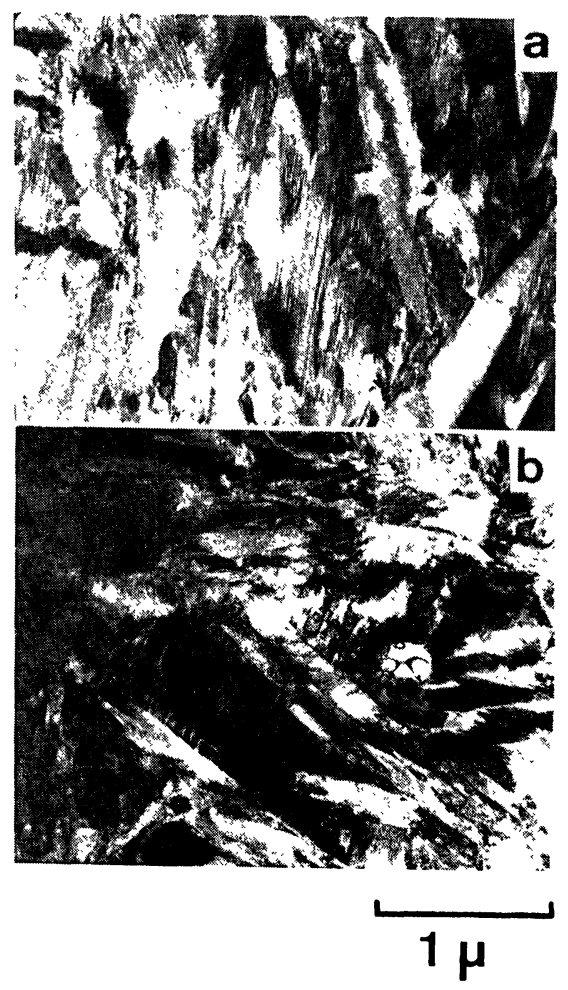

(a) $10 \mu$ below the surface

(b) $1 \mathrm{~mm}$ below the surface (Hs $90, \mathcal{N}=9 \times 10^{4}$ )

Photo. 1. Transmission electron micrographs of a work roll of cold strip mill (GWR). 
from the inner region to the surface.

\section{Changes in Half Value Breadth on Surface due to Rolling}

Figure 2 and 3 show the relationships between the number of contacts per rolling chance and the half value breadth measured at the surface upon completion of each rolling chance, for the case where rolling and dressing were repeated during actual operation. For the CWR, if the dressing amount is reduced to $0.05 \mathrm{~mm}^{\psi}$, the half value breadth is smaller than for the usual dressing.

This is considered to result from an accumulation of successive decreases in the half value breadth near the surface due to rolling contact fatigue. A decrease in the half value breadth with an increase in the number of rolling contacts is also observed in the GBR, as shown in Fig. 3.

The results in this section do not contradict the results of the studies on the half value breadth distribution of backup rolls by Shimoda et al., ${ }^{7)}$ and by Nagase et al.$^{8)}$ There is no difference in the measured values between the middle and end portions of the roll barrel.

\section{Model Experiment}

As described in Section II.2. 2, a half value breadth distribution containing a minimum was measured on a backup roll after use. A model experiment was performed to clarify the formation mechanism of this distribution. A rolling contact fatigue tester, made

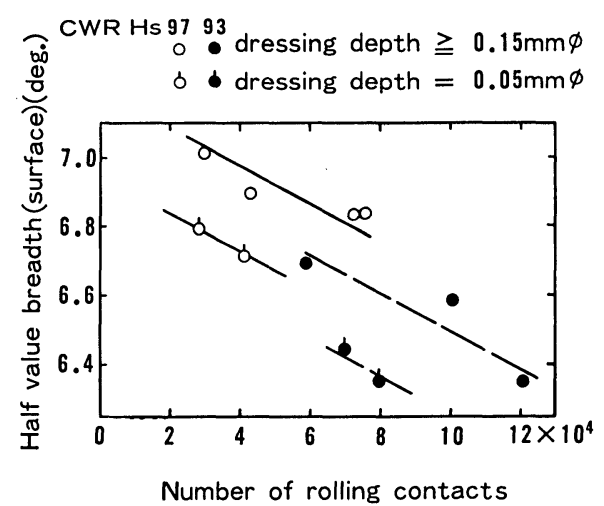

Fig. 2. Variation of the relationship between the half value breadth and $\mathcal{N}$ with different dressing depths, for work rolls of a cold strip mill (GWR).

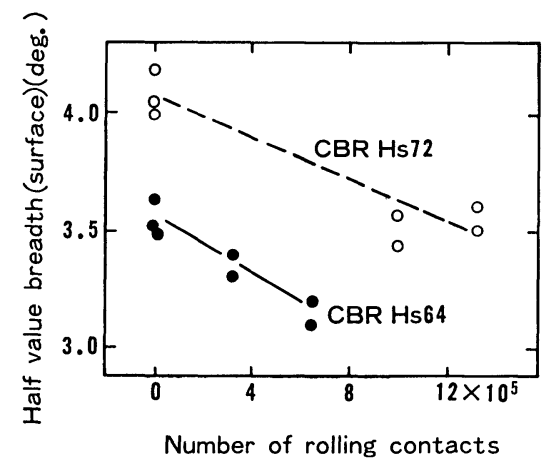

Fig. 3. Relationship between the half value breadth and $\mathcal{N}$ for backup rolls of a cold strip mill (CBR). by Shimazu Seisakusho, Ltd., was used for this experiment. This testing machine brings a disc specimen $100 \mathrm{~mm}$ dia. $\times 10 \mathrm{~mm}$ thickness into rolling contact with an SUJ 2 (Hs 95, same size) and applies a load to the specimen through a lever. The specimens were prepared so as to simulating a CBR, as shown in Table 1. An SNCM 8 bar was cut to the desired size and then heat treated. The maximum pressure used during the test, $P_{\max }$, was $84 \mathrm{~kg} / \mathrm{mm}^{2}$ and the half contact length, $L$, was $0.36 \mathrm{~mm}$. The rotation speed was $600 \mathrm{rpm}$, and the slip on contact was $0 \%$. Although no lubrication was applied, the temperature of the specimens remained below $60^{\circ} \mathrm{C}$ during the experiment. The number of contacts, $\mathcal{N}$, was varied from 0 to $9 \times 10^{5}$.

Measurements were made by visual observation, the determination of the distribution of the half value breadth in the depth direction, and optical and transmission electron microscopy. The measurement conditions for the half value breadth were the same as those for the backup rolls, shown in Table 3.

The results are described below. Visual observation revealed no cracks, spalling or deformation in the specimens. Figure 4 shows that the change in the half value breadth at the surface is small in the unfatigued material $(\mathcal{N}=0)$. But that for the fatigued material $\left(\mathcal{N}=9 \times 10^{5}\right)$, the half value breadth decreases towards the surface, in a zone up to $0.05 \mathrm{~mm}$ (approximately equal to $0.1 \mathrm{~L}$ ) below the surface.

Photograph 2 shows an optical micrograph of a section through a specimen surface after fatigue. A dark-etching region is observed within $30 \mu$ of the surface, which corresponds to the zone of reduced half value breadth. No metal flow was observed. Photograph 3 shows two transmission electron micrographs. In the zone suffering from no fatigue, the boundaries of the microstructures are clear. However, the structure boundaries $10 \mu$ below the surface of the fatigued specimen are vague and the structure itself resembles subgrains. The dark etching is considered to result from this change in structure.

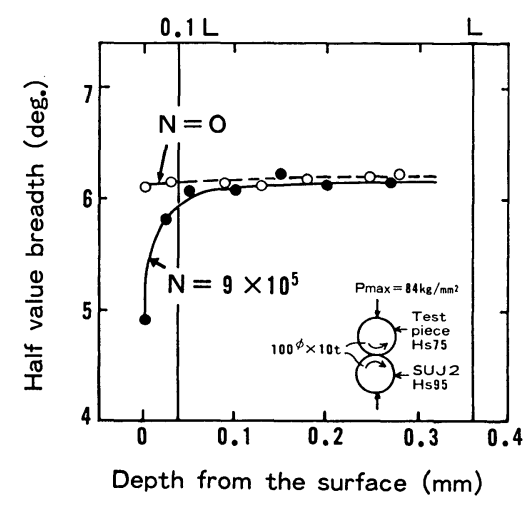

Fig. 4. Variation of the depth distribution of the half value breadth before and after the rolling contact model experiment. 


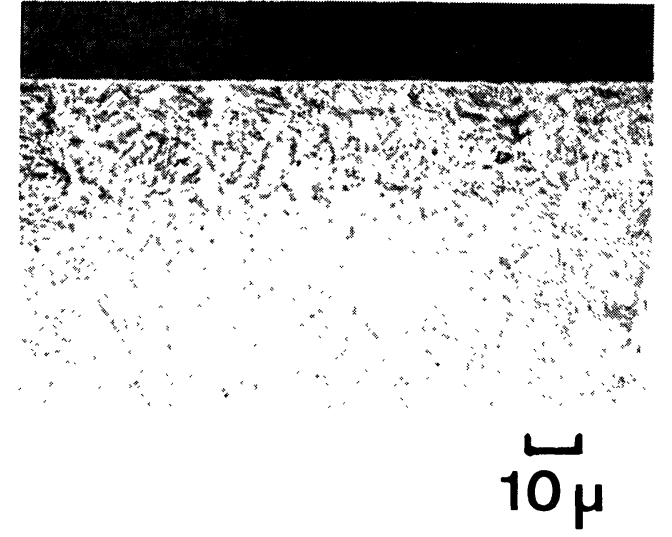

Photo. 2. Optical micrograph showing specimen microstructure of model experiment. ( $\mathcal{N}=9 \times 10^{5}$, cross-section parallel to the axis, nital etched)

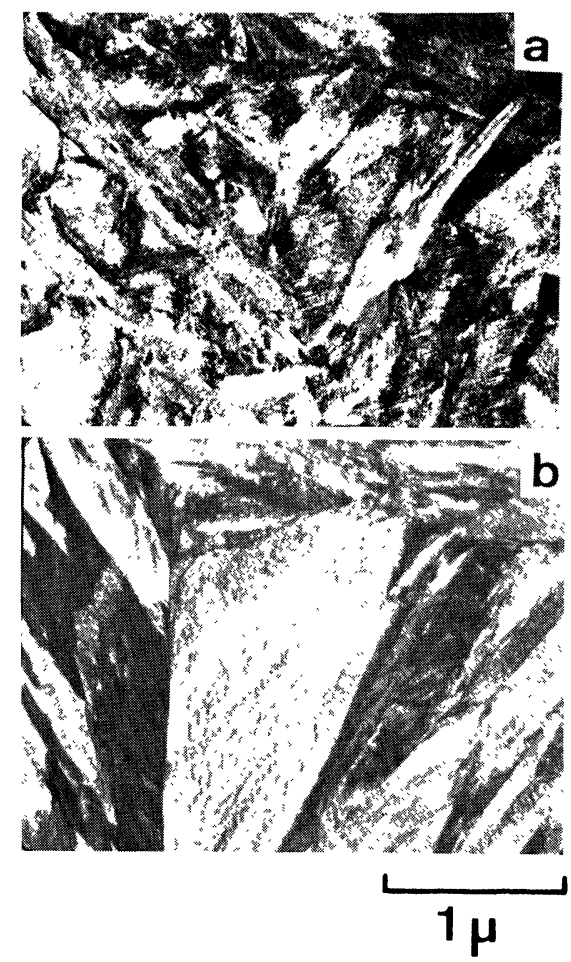

(a) $\mathcal{N}=9 \times 10^{5}: 10 \mu$ below the surface (b) $\mathcal{N}=0: 1 \mathrm{~mm}$ below the surface

Photo. 3. Transmission electron micrographs of specimens of model experiment.

\section{Discussion}

1. Changes in Half Value Breadth Associated with the Progress of Fatigue

Figure 5 shows the distributions of the half value breadth at various Hs levels. Column 4 shows the changes in the half value breadth distribution due to fatigue, and Column 5 shows changes if plastic flow is added. Column 6 shows the types of change in the half value breadth that are associated with fatigue, in accordance with the classification system of The Society of Materials Science, Japan. ") "A" indicates a three-stage increase and " $\mathrm{B}$ " indicates a threestage decrease. Columns 4 to 7 were prepared on the basis of the following observations:

\begin{tabular}{|c|c|c|c|c|c|c|}
\hline & \multirow{3}{*}{ Hs } & \multirow{3}{*}{$\begin{array}{c}\text { Experimental } \\
\text { result }\end{array}$} & \multicolumn{4}{|c|}{ Discussion } \\
\hline & & & \multicolumn{2}{|c|}{ Causes of change } & \multirow{2}{*}{$\begin{array}{l}\text { Type of } \\
\text { change } \\
\text { with } \\
\text { fatigue }\end{array}$} & \multirow{2}{*}{$\begin{array}{l}\text { Plastic } \\
\text { flow }\end{array}$} \\
\hline & & & Fatigue & $\begin{array}{l}\text { Fatigue + } \\
\text { Plastic flow }\end{array}$ & & \\
\hline I & $80 \sim$ & & & & B & $\begin{array}{c}\text { does not } \\
\text { occur }\end{array}$ \\
\hline II & $60 \sim 70 \mid$ & & $x$ & $x$ & B & occurs \\
\hline III & $\sim 50$ & مـ & $\frac{\Delta}{x}$ & مـ & A & occurs \\
\hline
\end{tabular}

b: half value breadth

$\mathrm{x}$ : depth from the surface

Fig. 5. Half value breadth depth distributions occurred by rolling contact. The dashed lines represent patterns before changing by fatigue or plastic flow.

(1) The half value breadth decreases due to fatigue in rolls of $\mathrm{Hs} 60$ or more (Type B), while it increases in rolls of $\mathrm{Hs} 50$ or less (Type A).

(2) In rolls of $\mathrm{Hs} 70$ or less, plastic flow occurs in the surface layer due to rolling contact fatigue. The half value breadth increases with plastic flow. In rolls of $\mathrm{Hs} 80$ or more, the plastic flow is small and negligible.

The above two points will now be discussed, Point (1) related to the phenomenon of the change in the half value breadth associated with fatigue is varying with Hs level. It has been shown by The Society of Materials Science, Japan, that in general Type A applies to annealed materials, while Type B applies to cold worked materials. ${ }^{6)}$ It is known that the half value breadth is related to the density of lattice defects, such as dislocations, stacking faults and point defects. ${ }^{10)}$ In materials having a narrow half value breadth, such as annealed materials, the lattice defect density is low initially, but microscopic plastic deformation is introduced into the structure by fatigue and the lattice defect density increases. This is considered to result in an increase in the half value breadth. In contrast to this, the initial lattice defect density is high in cold worked or hard heat-treated materials that have a wide half value breadth, and on fatiguing a decrease in the dislocation density occurs due to the channeling effect, and in case of a martensite structure, the tetragonal martensite lattices become isotropic. The decrease in the half value breadth with fatigue is considered to occur as a result of this.

A hardness level (or half value breadth level) corresponding to the transition between types $\mathrm{A}$ and $\mathrm{B}$ is therefore considered to exist. It can be estimated from Fig. 5 that this transition between types $A$ and B occurs at $\mathrm{Hs} 50$ to 60 . From Fig. 1, the half value breadth at the transition is about $2.5^{\circ}$ under the measurement conditions of this study.

Many studies have been made on the structural changes associated with fatigue. For example, Hayashi and Hatanaka, ${ }^{11)}$ state that a change from a cell 
structure to a subgrain structure, i.e., a kind of recovery, results in a decrease in the half value breadth. In the present work, transmission electron microscopy of hard heat-treated specimens, such as strip mill rolls and the specimens for the model experiment, indicates that the structure boundaries become vague after fatigue and that the structures come to resemble subgrains. Concerning point (2), the existence of a plastic flow layer has been observed by Shimoda et al. ${ }^{7)}$ on a CBR sleeve of Hs 48. The lower the hardness, the more plastic flow occurs. Taking account of Fig. 5, it seems that plastic flow occurs in rolls of $\mathrm{Hs} 50$ or less, and that plastic flow is negligible in rolls of $\mathrm{Hs} 80$ or more. For rolls of Hs 60 to 70, the mechanism is not completely clear. However, when the change in the half value breadth due to dressing is taken into consideration, an increase in the half value breadth does seem to occur, as in the case of rolls of Hs 50 or less.

\section{Formation Mechanism of Fatigue Damage Layers}

In this study, layers in which a change in the half value breadth occurred were detected within $0.1 \mathrm{~L}$ below the surface during actual rolling and in the model experiment. The changes in the half value breadth near the surface may also by caused by tempering owing to the generation of heat, in addition to fatigue and plastic flow. The fatigue and plastic flow are considered to be governed by Hertzian, tangential, residual and thermal stresses. These are examined separately below.

(1) Hertzian stresses

Figure 6 shows the radial (or depth) directional distribution of Hertzian stresses when tangential stresses are not present.1,12) Figure 7 shows the tangential directional distribution of the same stresses. ${ }^{13}$ ) Until now, $\tau_{\mathrm{xy} 45}$ (called also $\tau_{45}$ ) and $\tau_{\mathrm{xy} 90}$ (called also $\tau_{\mathrm{z}}$ ) have been pointed out as the stresses governing rolling contact fatigue (for example, p. 338 of Ref.

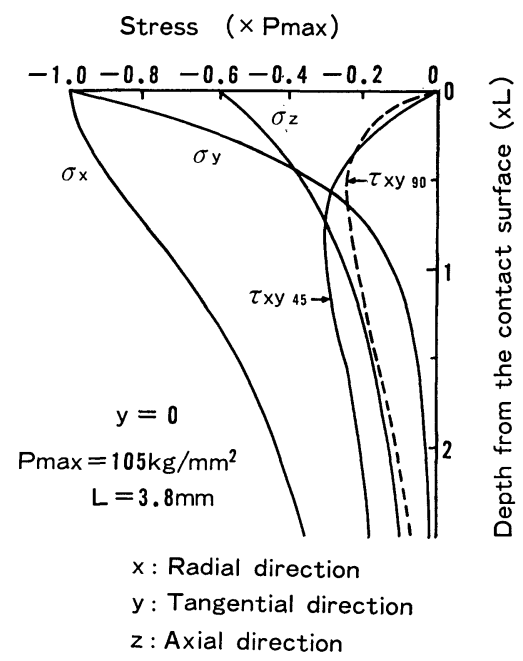

Fig. 6. Stress distribution below the contact surface between the work roll and the backup roll of a cold strip mill, with no tangential stresses. ${ }^{12)} \quad \tau_{\mathrm{xy} 90}$ is compiled from Ref. 1), p. 338, Table 17.1, and the dashed line represents its amplitude.
1)). These are stresses that have their maxima from $0.5 L$ to $0.8 L$ below the surface, and are not considered to bring about a change in the half value breadth within $0.1 \mathrm{~L}$ below the surface. Having a large stress gradient near the surface, $\sigma_{\mathrm{y}}$ and $\sigma_{\mathrm{z}}$ are likely to contribute to some extent to fatigue and plastic flow near the surface.

\section{(2) Tangential stresses}

Tangential stresses are generated by frictional forces acting on the roll surface. For CWR's and CBR's the value of $\mu$ (the frictional coefficient) between the backup roll and the work roll, and also between the work roll and the strip is about 0.03.14) Thus, if $P_{\max }=100 \mathrm{~kg} / \mathrm{mm}^{2}$, the tangential stresses are about $3 \mathrm{~kg} / \mathrm{mm}^{2}$, and their contribution to fatigue and plastic flow is small. This seems to apply also to HBR's.

(3) Residual stresses

The residual compressive stresses in the tangential and axial directions of a hardened material increase sharply near the surface. These residual stresses contribute to fatigue as mean stresses, and their contribution to plastic flow is also conceivable. The distributions of residual stresses in the depth direction in a CWR and a CBR were measured. The changes were small in comparison with those of the half value breadth in the depth direction, and no clear relationship could be obtained. Many points about residual stresses will require future clarification. (4) Thermal stresses

Heat is generated due to friction between the contacting surfaces of strip mill rolls. The rolls are cooled by a coolant. Thermal stresses are generated by the cyclic heat generation and cooling and are considered to cause fatigue. Kelly ${ }^{\mathbf{1 5})}$ has obtained for the rolling contact of cylinders having slip, a distribution of instantaneous maximum temperature below the surface, as shown in Fig. 8. As is apparent from this figure, a large temperature increase is observed very near the surface, i.e., within $0.1 \mathrm{~L}$ $(=0.124 \mathrm{~mm})$ of the surface. this corresponds fairly well to the zone where a change in the half value
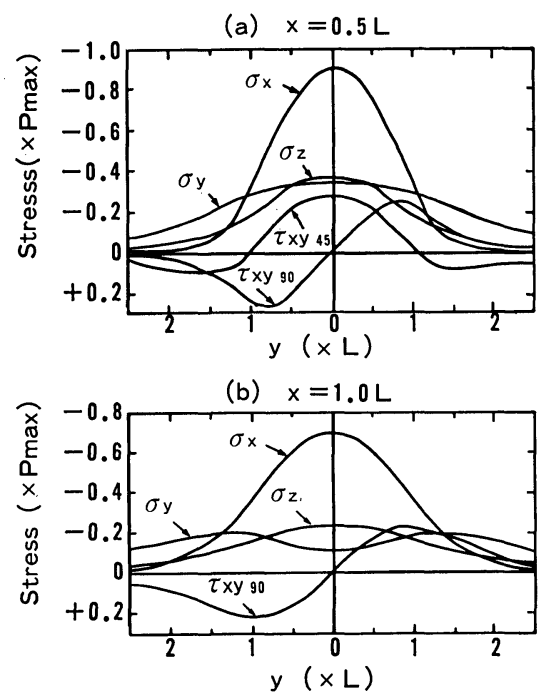

Fig. 7. Distributions of the same stresses as Fig. 6 in the tangential direction at depths of $0.5 \mathrm{~L}$ and $1.0 \mathrm{L.}^{13)}$ 


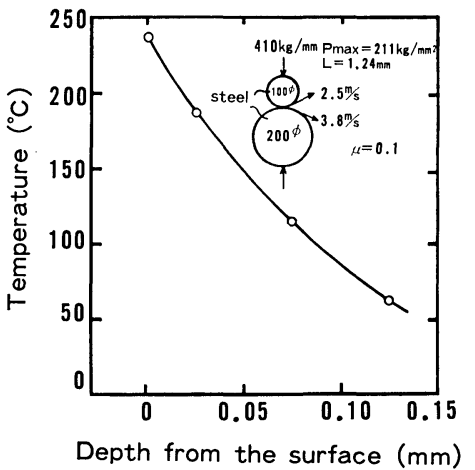

Fig. 8. Distribution of maximum temperature during rolling contact, compiled from the data of Kelly. ${ }^{14)}$

breadth was observed by the present authors, and thermal stresses are considered to be the main cause of fatigue and plastic flow. Kelly states that the thermal stresses generated in the example shown in Fig. 8 were to as large as $90 \mathrm{~kg} / \mathrm{mm}^{2}$. However, for the case of rolls for strip mills, slip, the coefficient of friction, $\mu$, and $P_{\max }$ are small compared with those in Kelly's work and accordingly the thermal stresses generated are considered to be smaller than $90 \mathrm{~kg} / \mathrm{mm}^{2}$.

\section{(5) Tempering}

It is possible that tempering takes place due to the generation of the heat mentioned in (4), and leads to a reduction in the half value breadth. In this study, since the maximum temperature was low, mainly recovery is considered to occur. It is inconceivable that the half value breadth should have increased due to tempering.

For backup rolls, the surface temperature during rolling is estimated to be below $200^{\circ} \mathrm{C}$ for both HBR's and CBR's. Since this temperature is below the tempering temperature (about $450^{\circ} \mathrm{C}$ ) during roll making, further tempering is not considered to take place. In the case of backup rolls of $\mathrm{Hs} 50$ or less, since only increases in the half value breadth are observed after use, it can be said that there is no tempering effect.

For CWR's, the surface temperature is estimated to rise up to $300^{\circ} \mathrm{C}$, due to friction with the strip. This temperature is higher than the tempering temperature (about $150^{\circ} \mathrm{C}$ ) during roll making. However, the tempering effect is considered to be small during rolling because the decrease in the half value breadth is small at temperatures as low as $300^{\circ} \mathrm{C}$ and the holding time is short.

To sum up the above, the changes in the half value breadth observed below the surfaces of strip mill rolls are considered to have been caused mainly by fatigue and plastic flow due to various stresses, for example thermal stresses. The damage to the material microstructures detected from the changes in the half value breadth is mostly caused by fatigue and can be called fatigue damage.

\section{Prevention of Fatigue Fracture Accidents and Reduc- tion of Roll Dressing Amounts}

As discussed in the preceding section, the fatigue damage observed in this study is not due to Hertzian shear stresses $\left(\tau_{\mathrm{xy} 45}\right.$ and $\left.\tau_{\mathrm{xy} 90}\right)$, but is caused by various stresses, mainly thermal stresses, near the surface. Karashima $^{2)}$ has stated that microstructures change with fatigue, and that substructures (cells or subgrains) and dislocation distributions reach to a constant state. Furthermore, Karashima ${ }^{2}$ and Hayashi and Hatanaka, ${ }^{11)}$ have stated that fatigue cracks are initiated by the development of substructures associated with fatigue. Since the half value breadth changes in response to the development of such substructures, it is an effective means of preventing fatigue fractures by forecasting the occurrence of fatigue cracks.

In general, fatigue fracture accidents occurring in strip mill rolls, such as spalling and case crashing, are divided into those that are attributable to the roll interior and those that are attributable to the roll surface. ${ }^{16-18}$ ) The former are caused by internal defects such as inclusions and cannot be prevented by the detection of the fatigue damage near the surface.

Further studies are required in order to establish the half value breadth as a measure of fatigue damage near the surfaces of strip mill rolls, and to apply it to the prevention of fatigue fracture accidents and the minimization of dressing amounts. It is necessary to clarify both the quantitative relationship between the rate of change in the half value breadth at the surface and the initiation of fatigue cracks, and the effects of the grade of the roll steel, the roll making conditions, rolling conditions, etc. Furthermore, the actual measurement methods must be examined-for example, a method for detecting fatigue damage by continuously measuring the half value breadth at the surface of rotating rolls.

As a result of this study, the fatigue damage depth was observed quantitatively and the standard regular dressing amount at Kimitsu Works was revised. This has led to reduction in roll consumption of a half. No problems, such as spalling, have occurred since this revision.

\section{Conclusions}

The fatigue damage occurring near the surfaces of hot rolling backup rolls, cold rolling work rolls and cold rolling backup rolls used in steel strip mills was studied using the half value breadth of X-ray diffraction lines and the following results were obtained:

(1) The fatigue damage occurs within $0.03 \mathrm{~L}$ ( $L$ : half contact length) below the surface for cold rolling work rolls, and within $0.1 \mathrm{~L}$ for other rolls.

(2) For rolls with a surface hardness of Hs 60 or more, the half value breadth at the surface decreases with an increase in the number of rolling contacts. The half value breadth at the surface increases for rolls of $\mathrm{Hs} 50$ or less.

(3) The distribution of the half value breadth below the roll surface in the depth direction was classiffed into the following three types by $\mathrm{Hs}$ hardness:

i) Monotonically decreasing (from the interior 
to the surface of the roll) (Hs 80 or more; cold rolling work rolls)

ii) Abruptly increasing after a decrease (Hs 60 70 ; cold rolling backup rolls and some of the hot rolling backup rolls)

iii) Monotonically increasing ( $\mathrm{Hs} 50$ or less; some of the hot rolling backup rolls)

(4) The distribution of the half value breadth in (3) is considered to result from fatigue. In case materials of $\mathrm{Hs} 70$ or less there is also an effect of plastic flow.

(5) The fatigue and plastic flow observed within $0.1 L$ of the roll surface are considered to be caused by various stresses, mainly thermal stresses.

\section{REFERENCES}

1) T. Ishibashi: Kinzoku no Hiro to Hakai no Boshi, Yokendo, Tokyo, (1967), 335.

2) S. Karashima: Kinzoku Zairyo no Hiro, Jap. Inst. Metals, (1973), 57.

3) M. A. Miner: Trans. ASME, 67 (1945).

4) S. Taira and K. Honda: Bull. Japan Soc. of Mech. Eng., 4 (1961), No. 14, 230.
5) The 2nd Division of the Committee for X-ray Study on Deformation and Fracture of Solid Materials: J. Soc. Mat. Sci. Japan, 18 (1969), 679.

6) The 2nd Division of the Committee for X-ray Study on Deformation and Fracture of Solid Materials: J. Soc. Mat. Sci. Japan, 19 (1970), 714.

7) H. Shimoda, Y. Arakida and T. Shibazaki: Zairyo Shiken, 11 (1962), 663.

8) M. Nagase, S. Shimizu, H. Shimizu, H. Tabe, K. Kudo and H. Goto: Tetsu-to-Hagané, 56 (1970), 1201.

9) Soc. Mat. Sci. Japan: X-sen Oryoku Sokuteiho, Yokendo, Tokyo, (1971), 244.

10) S. Sato: X-sen Zairyo Kyodo Gaku, ed. by Soc. Mat. Sci. Jap., Yokendo, Tokyo, (1973), 301.

11) K. Hayashi and K. Hatanaka: J. Soc. Mat. Sci. Japan, 20 (1971), 1244.

12) S. Timoshenko and J. N. Goodier: Theory of Elasticity, McGraw-Hill Book Co., New York, (1951), 381.

13) E. I. Radzimovsky: Illinois Bulletin, Ser. No. 408, (1953).

14) M. D. Stone: Iron Steel Eng., 38 (1961), June, 67.

15) B. W. Kelly: Handbook of Mechanical Wear, ed. by G. Lipson and L. V. Colwell, The University of Michigan Press, Michigan, (1961), 155.

16) K. Akabori: J. Japan Soc. Tech. Plast., 6 (1965), 329.

17) K. Kudo: JSW Technical Review; (1969), No. 26, 3053.

18) M. Nakagawa: The Hitachi Hyoron, 58 (1976), 719. 